\title{
The VS catalytic RNA replicates by reverse transcription as a satellite of a retroplasmid
}

\author{
John C. Kennell, ${ }^{1,3}$ Barry J. Saville, ${ }^{2,4}$ Sabine Mohr, ${ }^{1}$ Martin T.R. Kuiper, ${ }^{1,5}$ Josanne R. Sabourin, ${ }^{1}$ \\ Richard A. Collins, ${ }^{2}$ and Alan M. Lambowitz ${ }^{1,6}$ \\ ${ }^{1}$ Departments of Molecular Genetics, Biochemistry, and Medical Biochemistry, The Ohio State University, Columbus, Ohio \\ 43210-1292 USA; ${ }^{2}$ Departments of Botany and Molecular and Medical Genetics, University of Toronto, Toronto, Ontario \\ M5S 1A8, Canada
}

The mitochondria of certain natural isolates of Neurospora contain both the Varkud plasmid, which encodes a reverse transcriptase, and a small unrelated RNA (VS RNA) that performs RNA-mediated self-cleavage and ligation reactions. Here, we show that VS RNA is transcribed from a VS plasmid DNA template by the Neurospora mitochondrial RNA polymerase using a promoter located immediately upstream of the RNA self-cleavage site that generates monomeric transcripts. VS RNA is then reverse transcribed by the Varkud plasmid reverse transcriptase to yield a full-length $(-)$ strand cDNA, a predicted replication intermediate. Combined with previous genetic evidence, our results indicate that the VS plasmid replicates by reverse transcription as a satellite of the Varkud plasmid. This mode of replication, unprecedented for a satellite RNA, likely reflects the promiscuity of the Varkud plasmid reverse transcriptase, which does not require a specific primer to initiate cDNA synthesis. Our findings indicate how primitive reverse transcriptases with similar relaxed specificity could have facilitated the evolution of new retroelements.

[Key Words: Mitochondrial plasmid; Neurospora; retroelement; reverse transcriptase; ribozyme]

Received October 26, 1994; revised version accepted December 21, 1994.

Satellite RNAs, whose propagation is dependent on an unrelated helper virus, have been found in plants and animals (Roossinck et al. 1992; Taylor 1992). Most satellite RNAs, including virusoids in plants and hepatitis $\delta$ virus in animals, are believed to replicate via a complementary RNA intermediate using a rolling circle mechanism in which an RNA self-cleavage domain is used to generate monomer-length RNAs (Symons 1992; Taylor 1992). Different satellite RNAs contain different RNA self-cleaving domains, denoted hammerhead, hairpin or hepatitis $\delta$ virus ribozyme, but all use a common cleavage pathway yielding products having $2^{\prime}, 3^{\prime}$-cyclic phosphate and 5' OH termini (Symons 1992). In most cases, the polymerase that replicates the satellite RNA has not been conclusively identified. However, recent studies have provided evidence that some plant RNA virus satellite RNAs replicate by using a helper virus RNA-dependent RNA polymerase complex (Wu et al. 1991, 1993; Song and Simon 1994).

Present addresses: ${ }^{3}$ Department of Biological Sciences, Southern Methodist University, 220 Fondren Science, Dallas, Texas 75275-0376 USA; ${ }^{4}$ Department of Botany, Erindale Campus, University of Toronto, Mississauga, Ontario L51 1L6, Canada; ${ }^{5}$ Keygene n.v., Agro Business Park 90,6700 AE Wageningen, The Netherlands.

${ }^{6}$ Corresponding author.
The mitochondria of certain Neurospora spp. natural isolates contain an abundant noncoding RNA, denoted VS RNA, which performs RNA-mediated self-cleavage and ligation reactions. A less abundant DNA form, VS plasmid DNA, is also present (Fig. 1, left; Saville and Collins 1990, 1991). The ribozyme domain of VS RNA has a novel secondary structure, but like other RNA selfcleaving domains, yields products having 2', $3^{\prime}$-cyclic phosphate and 5' OH termini (Saville and Collins 1990; Beattie et al. 1995). The VS RNAs found in mitochondria include linear and circular monomers and concatemers, and the VS plasmid DNAs include closed-circular double-stranded DNA monomers and concatemers.

The Neurospora strains that contain the VS plasmid invariably contain a larger mitochondrial (mt) plasmid, the Varkud (V) plasmid, which is not homologous to VS. The $\mathrm{V}$ plasmid and its close relative, the Mauriceville (M) plasmid, denoted retroplasmids, are closed-circular DNAs of 3.7 and $3.6 \mathrm{~kb}$, respectively, that encode a reverse transcriptase (RT) (Collins et al. 1981; Akins et al. 1988; Kuiper and Lambowitz 1988; Kuiper et al. 1990). The retroplasmids appear to replicate by synthesizing a monomer-length transcript that is reverse transcribed into DNA (Kuiper and Lambowitz 1988; Kennell et al. 1994). Remarkably, the retroplasmid transcript contains a $3^{\prime}$ tRNA-like structure similar to those of certain plant 


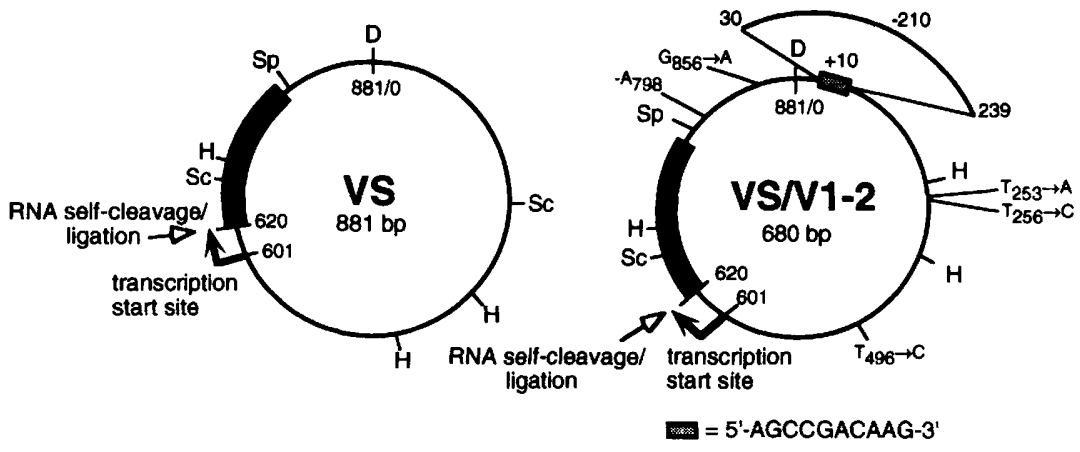

Figure 1. Maps of the VS and VS/V1-2 plasmids. The VS/V1-2 plasmid is a deletion derivative of the VS plasmid in which nucleotides $30-239$ have been replaced by 10 nucleotides of unknown origin (shaded box). The VS/V1-2 plasmid also has five single-base mutations, which are indicated. The region of VS RNA required for RNA self-cleavage is indicated in black (VS620-773; Guo et al. 1993). The transcription start site and RNA self-cleavage/ligation site are indicated by solid and open arrows, respectively. Nucleotide position numbers for both plasmids refer to the VS plasmid sequence (Saville and Collins 1990). Restriction enzyme sites are abbreviated: (D) DraI, (H) HincII, (Sc) ScaI, (Sp) SspI.
RNA viruses, and the retroplasmid RT functions analogously to the viral RNA-dependent RNA polymerases in recognizing this structure and initiating cDNA synthesis de novo (i.e., without a primer) opposite the $C$ residue at position 2 (position C2) of the 3' CCA sequence (Kuiper and Lambowitz 1988; Wang and Lambowitz 1993a). In addition to de novo initiation, which is unprecedented for a DNA polymerase, the retroplasmid RT can also use various DNA or RNA primers to initiate cDNA synthesis at the $3^{\prime}$ end or an internal region of the retroplasmid transcript (Wang and Lambowitz 1993a; Kennell et al. 1994). In contrast to retroviral RTs, however, the primers are not complementary to the RNA template and accurate initiation depends on the ability of the retroplasmid RT to recognize specific sequence or structural features of the RNA template (Wang and Lambowitz 1993a). The characteristics of the retroplasmid RT are expected for a primitive RT that evolved from an RNA-dependent RNA polymerase and was ancestral to other RTs and DNA polymerases (Wang and Lambowitz 1993a). The retroplasmid RT is phylogenetically related to bacterial retron and group II intron RTs, which are also believed to be primitive RTs (Xiong and Eickbush 1990; Eickbush 1994).

Circumstantial evidence suggested that the VS plasmid might be a satellite of the $\mathrm{V}$ retroplasmid. All eleven natural isolates of Neurospora in which VS was found also contain the retroplasmid, whereas two other natural isolates, including the Mauriceville strain, contain only the retroplasmid (Guo et al. 1993; E.R.M. Tillier, D.M. De Abreu, and R.A. Collins, unpubl.). In addition, experiments in which the plasmids were transferred between strains via transient hyphal fusions showed that the VS plasmid could be transferred only in association with the $\mathrm{V}$ retroplasmid, whereas the $\mathrm{V}$ retroplasmid could be transferred independently of VS /Collins and Saville 1990). These findings, together with the absence of long open reading frames (ORFs) in the VS plasmid and the failure to detect $(-)$ strand VS RNAs in mitochondria, raised the possibility that the VS plasmid replicates by reverse transcription as a satellite of the retroplasmid.

In the present work, we provide biochemical evidence that the VS plasmid replicates via reverse transcription.
We show that the VS plasmid DNA is transcribed by the Neurospora mt RNA polymerase to yield VS RNA and that VS RNA is reverse transcribed by the retroplasmid RT to yield full-length $(-\mid)$ strand cDNA, a predicted replication intermediate. The ability of the $\mathrm{V}$ retroplasmid to support replication of a satellite RNA likely reflects the promiscuity of its RT, which does not require a specific primer to initiate of cDNA synthesis. Our findings indicate how primitive RTs with similar relaxed specificity could have led to the evolution of new retroelements.

\section{Results and Discussion}

In vitro transcription of VS DNA by mt RNA polymerase

The synthesis of VS RNA was investigated by in vitro transcription experiments using plasmid $\mathrm{pD} 7$, which contains a monomer clone of VS DNA. Figure 2 shows that when pD7 was digested with ScaI, HincII, SspI, or $X b a I$ and incubated with $\mathrm{mt}$ lysates from strains that contained or lacked plasmids, runoff transcripts of 78 , 99,185 , and 300 nucleotides, respectively, were synthesized. A control showed that no transcripts were synthesized from the linearized vector, pTZ18R/XbaI (pTZ) $X b a \mathrm{I})$. The sizes of the $\mathrm{pD} 7$ runoff transcripts indicate that the major in vitro transcription start site is located around VS position 600. Primer extension mapping of in vitro transcripts synthesized from $\mathrm{pD} 7 /$ s spI showed that the predominant $5^{\prime}$ end corresponds to either G601 or T602 (not shown). Because all transcription start sites described previously for Neurospora mt RNA polymerase correspond to a G-residue, we infer that the major initiation site is most likely G601 (indicated by a star in Fig. 2).

As shown in Figure 2 (bottom), the sequence around the in vitro transcription start site in VS DNA is an $8 / 11$ match to the Neurospora mt DNA promoter consensus sequence and is preceded by an upstream AT-rich region characteristic of active promoters in Neurospora mtDNA (Kubelik et al. 1990). Notably, the transcription start site is only $\sim 20$ nucleotides upstream of the VS 


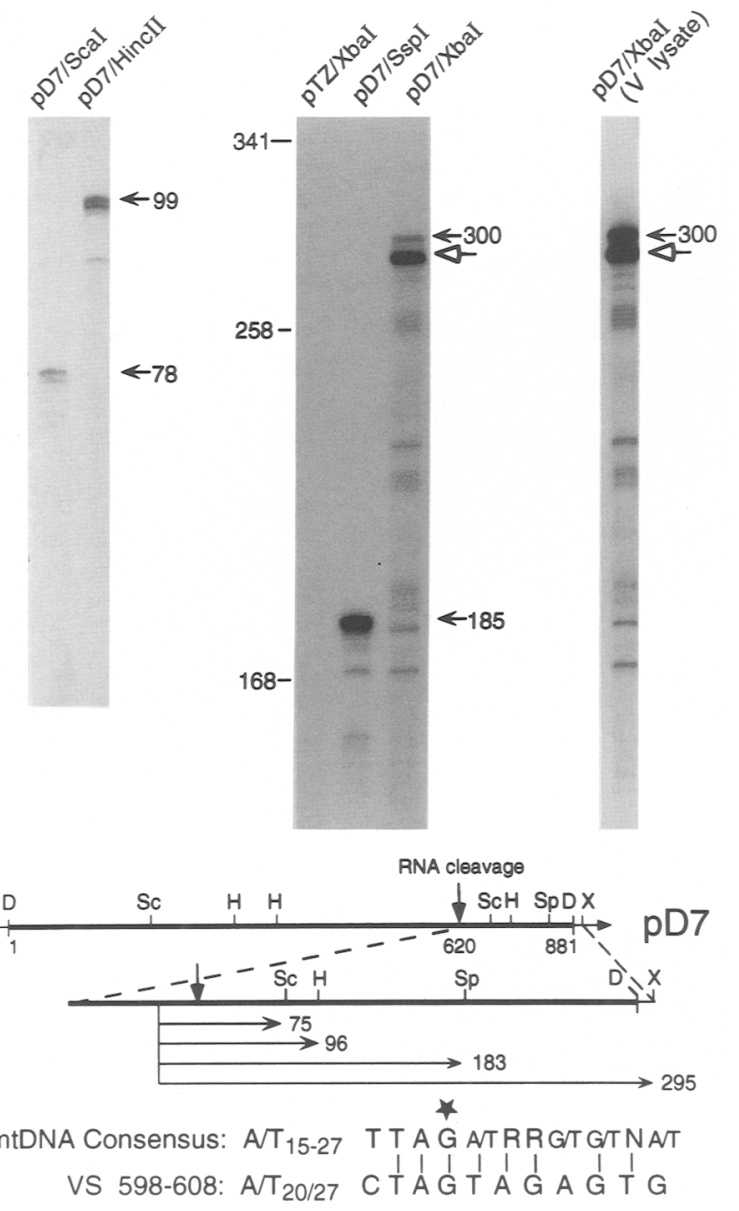

Figure 2. In vitro transcription of VS DNA. One microgram of plasmid $\mathrm{pD} 7$, which contains monomer VS plasmid, or the vector pTZ18R (pTZ), was digested with restriction enzymes (indicated) and transcribed with $\mathrm{mt}$ lysates from [poky) 13-6 (left and middle) or the Varkud strain (right), as described in Materials and methods. In vitro transcripts were analyzed by electrophoresis in a $12 \%$ polyacrylamide $/ 8 \mathrm{M}$ urea gel (left) or a $6 \%$ polyacrylamide $/ 8 \mathrm{M}$ urea gel (same gel for middle and right). The open arrow indicates a band that likely results from selfcleavage of in vitro transcript $\mathrm{pD} 7 / \mathrm{XbaI}$. Numbers to the left of the autoradiograph indicate positions and sizes of $5^{\prime}$ end-labeled Sau3AI fragments of Bluescribe (+ | vector (Stratagene, La Jolla, CA) used as molecular weight markers. Numbers to the right indicate estimated sizes (nucleotides) of the in vitro transcripts. The schematic shows a partial restriction map of VS DNA and expected sizes of runoff transcripts beginning at position 601 . The bottom compares the sequence flanking the transcription start site of the VS plasmid with the Neurospora mtDNA promoter consensus sequence (Kubelik et al. 1990). The star indicates the putative initiating nucleotide, G601. Restriction enzymes are abbreviated: (D) DraI; $(\mathrm{Sc})$ ScaI, $(\mathrm{H})$ HincII, (Sp) SspI, and $(\mathrm{X}) \mathrm{XbaI}$.

RNA self-cleavage site. The transcripts $\mathrm{pD} 7 / \mathrm{XbaI}$ and $\mathrm{pD7} /$ SspI contain the minimal ribozyme domain /VS620 to 773 ; see Fig. 1), and the longer pD7/XbaI transcript appears to be efficiently cleaved at the expected position (prominent band indicated by open arrow). The location of the in vitro transcription start site relative to the $5^{\prime}$ end of linear VS RNA suggests that VS RNA monomers are synthesized by transcription of circular or multimeric VS plasmid DNA followed by RNA self-cleavage.

\section{VS RNA is reverse transcribed}

The analysis of VS cDNA synthesis was faciliated by using a mutant Varkud strain, V1-2, which accumulates a suppressive variant of the $\mathrm{V}$ retroplasmid (V1-2 plasmid) leading to elevated RT activity (Akins et al. 1989; Kuiper et al. 1990). The V1-2 strain contains a deletion derivative of the VS plasmid, denoted VS/V1-2, in which nucleotides 30-239 of VS are replaced by 10 nucleotides of unknown origin (Fig. 1, right). The VS/V1-2 plasmid also has five single-base mutations compared to VS. We confirmed that the VS/V1-2 plasmid uses the same in vitro transcription start site and RNA self-cleavage site as the wild-type VS plasmid (not shown). In addition to the above plasmids, the V1-2 strain also contains a very small deletion derivative of the retroplasmid $/ \mathrm{V} 1-2 / \Delta \mathrm{l}$; $\sim 250$ bp; S. Mohr, B.J. Saville, R.A. Collins, and A.M. Lambowitz, unpubl.).

To determine whether the VS RNAs are reverse transcribed, mt RNP particles from the Varkud and V1-2 strains were incubated with $\left[{ }^{32} \mathrm{P}\right] \mathrm{dCTP}+$ other dNTPs, and ${ }^{32} \mathrm{P}$-labeled cDNAs synthesized from endogenous RNA templates were hybridized to Northern blots of $m t$ RNAs from Neurospora strains that contain or lack the $\mathrm{mt}$ plasmids. Figure 3 shows that the ${ }^{32}$ P-labeled cDNAs synthesized in both strains hybridized to the full-length transcripts of the $\mathrm{M}, \mathrm{V}$, or $\mathrm{V} 1-2$ retroplasmids $(3.6$ or 3.7 $\mathrm{kb}$ and to the related V1-2/ 1 RNA in the VI-2 strain. Strikingly, the ${ }^{32} \mathrm{P}$-labeled cDNAs from both strains hybridized strongly to VS and VS/V1-2 RNAs, whereas no hybridization was observed to most other abundant RNAs, for example, the large rRNA or coxI and cob mRNAs. The hybridization of the ${ }^{32} \mathrm{P}$-labeled cDNAs synthesized in the Varkud strain to the mt small rRNA (SSU rRNA) likely reflects reverse transcription of a Varkud strain-specific, 4.9-kb hybrid RNA, which consists of the $3.7-\mathrm{kb} V$ plasmid transcript with a $1.2-\mathrm{kb}^{\prime}$ leader derived from the mt small rRNA (Akins et al. 1988; Chiang et al. 1994). The 4.9-kb RNA is detected as a weak, diffuse band in this Varkud RNA preparation. In analogous experiments Southern hybridizations to restriction digests of DNA preparations likewise showed that the ${ }^{32} \mathrm{P}$-labeled cDNAs hybridized primarily to the retroplasmid and VS plasmid DNAs, with little if any hybridization to mtDNA restriction fragments encoding mRNAs (not shown). Together, these findings show that the VS and VS/V1-2 RNAs are preferred substrates for reverse transcription in $m$ t RNP particles.

For further analysis, ${ }^{32} \mathrm{P}$-labeled cDNAs synthesized in ribonucleoprotein (RNP) particles from the $\mathrm{V}$ or V1-2 strain were hybridized to dot blots of the M13-cloned $1+1$ and $(-)$ strands corresponding to the $\mathrm{V}$ and VS plasmids. The M13 vectors were included as controls. Time course experiments showed that cDNA synthesis for both the large and small plasmids continued for at least $30 \mathrm{~min}$ and that the ${ }^{32} \mathrm{P}$-labeled cDNAs isolated at all times hy- 

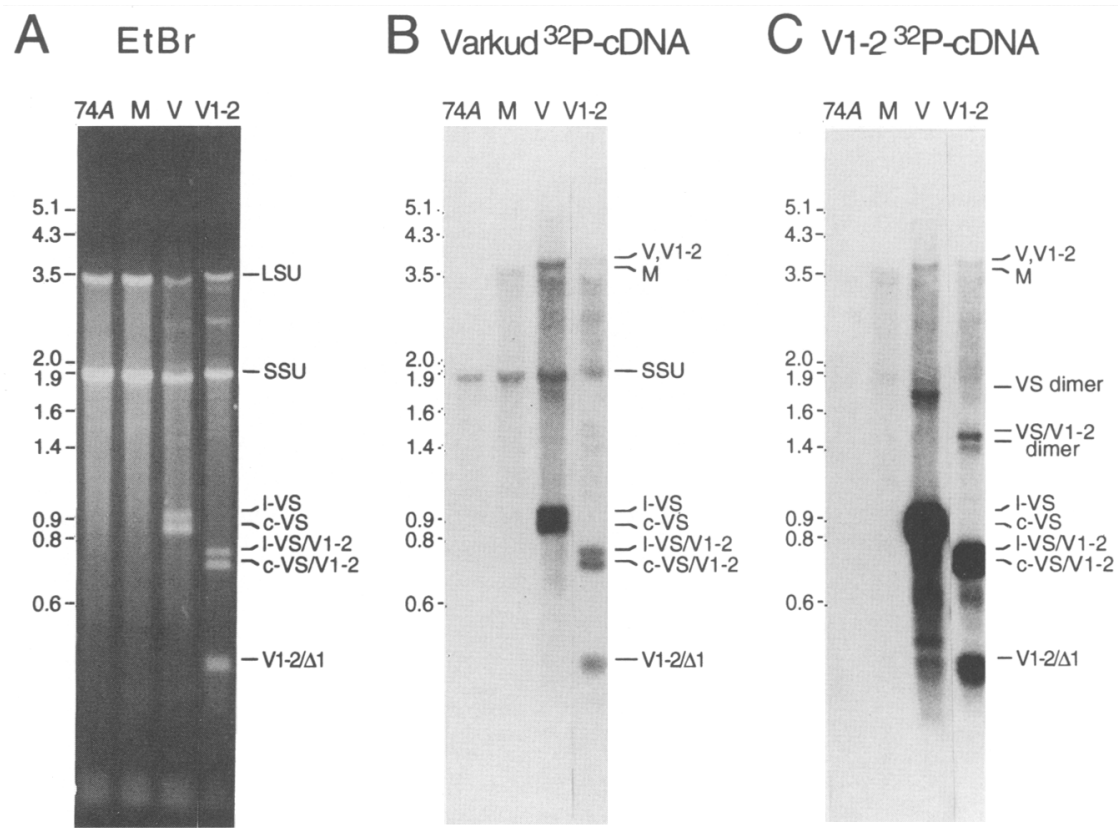

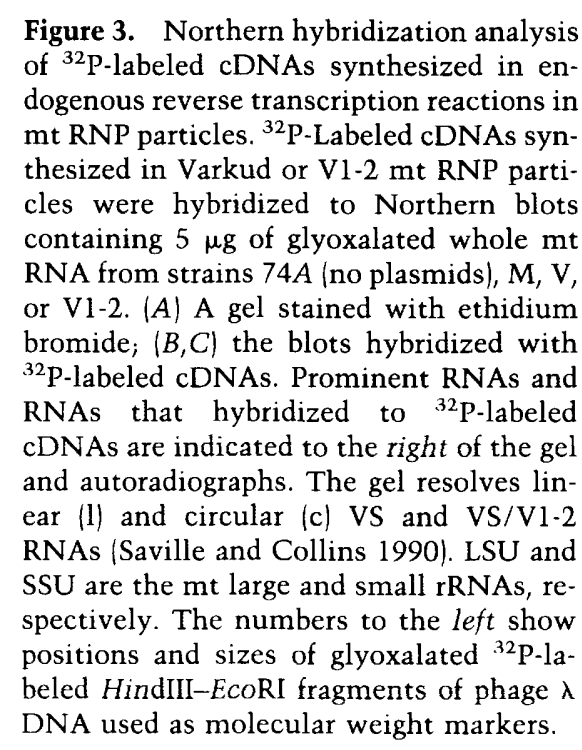

bridized preferentially to the $|+|$ strands of the plasmids, indicating that $(-)$ strand cDNAs are synthesized (Fig. 4). The dot blots, which provide a more quantitative comparison than the Northern hybridizations, indicate that the level of reverse transcription of VS RNA is relatively low in the wild-type $V$ strain but much higher for the VS/V1-2 plasmid in the V1-2 strain. Although the dot blots for both strains show some hybridization to the $(-)$ strands of the $\mathrm{V}$ and VS plasmids, this mostly reflects cross-hybridization rather than $(+\mid)$ strand synthesis in this experiment, because the ratio of $(+)$ to $(-)$ strand hybridization was unaffected by actinomycin $D$, an inhibitor of DNA-directed DNA synthesis (Fig. 4, bottom). In other dot blot experiments with V1-2 mt RNP particles, we showed that reverse transcription of VS/VI-2 RNA is inhibited by pretreatment with RNase $A+T_{I}$ or with micrococcal nuclease (not shown), confirming that an intact RNA template is required. Additionally, we confirmed that reverse transcription is dependent on all four deoxynucleotides, that ribonucleotides could not substitute for deoxyribonucleotides, and that the ${ }^{32} \mathrm{P}-\mathrm{la}$ beled products are sensitive to DNase and insensitive to RNase (not shown). Comparisons of VS/V1-2 and retroplasmid reverse transcription showed that both have similar optima for $\mathrm{Mg}^{2+}(1-5 \mathrm{mM}), \mathrm{pH}(\sim 8.0)$, and temperature $\left(45-50^{\circ} \mathrm{C}\right)$ and were equally inhibited by substitution of $\mathrm{Mg}^{2+}$ with $\mathrm{Mn}^{2+}$ or $5 \mathrm{~mm}$ EDTA (data not shown|, as expected for cDNA synthesis by the same enzyme.

\section{Sucrose gradient analysis of RNP particles}

Sucrose gradient analysis was carried out to determine whether the large and small plasmid RNAs are reverse transcribed in separate RNP particles. The gradient pro- file shows that linear and circular VS/VI-2 RNAs sedimented with a peak at 17S-20S (Fig. 5A; fractions 4-8), whereas the monomer-length retroplasmid transcripts detected by Northern hybridization sedimented with a peak at 27S-29S (fractions 7-9; not shown). Lesser amounts of both plasmid RNAs were broadly distributed through the gradient ahead of the peak, possibly reflecting aggregation. To assay RT activity associated with the RNP particles, the sucrose gradient fractions were incubated with $\left[{ }^{32} \mathrm{P}\right] \mathrm{dCTP}$ plus other dNTPs, and ${ }^{32} \mathrm{P}$-labeled cDNA synthesized in endogenous reactions were analyzed by gel electrophoresis and by hybridization to Northern blots of total mt RNAs from the Varkud strain. Figure 5, B and C, shows that the RNP particles in gradient fractions 4 and 5 synthesized VS/V1-2 cDNA extending up to the full length of the monomer plasmid, whereas the RNP particles in later gradient fractions synthesized both VS/V1-2 and the larger retroplasmid cDNAs.

The proteins in gradient fractions were analyzed by SDS-PAGE and immunoblotting with an antibody against the retroplasmid RT (Kuiper et al. 1990). Figure $5 \mathrm{D}$ shows that gradient fractions 4-6, which synthesize VS/V1-2 cDNAs, do contain the $81-\mathrm{kD}$ retroplasmid RT. The amount of the RT protein in most of the other gradient fractions was too low to be detected immunochemically, but RT activity in these fractions (Fig. 5B) paralleled the distribution of the retroplasmid transcript detected by Northern hybridization (not shown).

In additional experiments, we confirmed by nondenaturing gel electrophoresis that both wild-type VS and VS/ V1-2 RNAs are reverse transcribed in discrete, small RNP particles, separate from the larger retroplasmid RNP particles (J.R. Sabourin, E.J. Vidunas, and A.M. Lambowitz, unpubl.). Furthermore, the synthesis of fulllength VS and VS/V1-2 cDNAs in endogenous reverse 

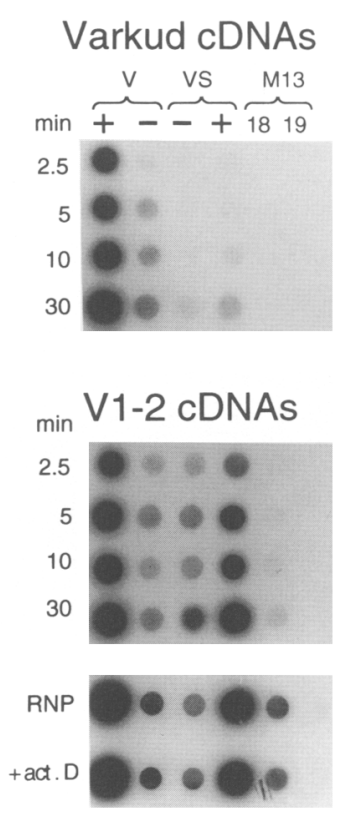

Figure 4. Dot blot hybridization of ${ }^{32} \mathrm{P}$-labeled cDNAs synthesized in endogenous reverse transcription reactions to the $1+1$ and $(-)$ strands of the V and VS plasmids. ${ }^{32} \mathrm{P}$-Labeled cDNAs were synthesized in Varkud and V1-2 mt RNP particles and hybridized to dot blots of $(+1$ and $|-|$ strands corresponding to the V plasmid (M13 phage M92 and M94, respectively; the M and $V$ plasmids have $97 \%$ sequence identity $\mid$; the $|+|$ and $\mid-1$ strands of the VS plasmid (M13 phage V18 and V19, respectively); and the single-strand M13mpl 8 and $M 13 \mathrm{mpl} 19$ vector DNAs. In the time course experiments, the blots were hybridized to ${ }^{32} \mathrm{P}$-labeled cDNAs synthesized in endogenous reverse transcription reactions of $2.5,5,10$, and $30 \mathrm{~min}$. (Bottom) Blots hybridized with ${ }^{32} \mathrm{P}$-labeled cDNAs synthesized in V1-2 RNP particles in the absence or presence of actinomycin $\mathrm{D}$ (act. D; $100 \mu \mathrm{g} / \mathrm{ml}$ ). We confirmed that the actinomycin D preparation completely inhibited DNA-directed DNA synthesis by Sequenase (not shown).

transcription reactions was confirmed by polyacrylamide gel electrophoresis and by restriction enzyme analysis of the gel-isolated, ${ }^{32} \mathrm{P}$-labeled cDNAs, after hybridization to unlabeled $|+|$ strand DNA or using enzymes that cut single-stranded DNAs (not shown).

\section{Identification of putative cDNA initiation sites in VS RNAs}

Because the retroplasmid RT ordinarily initiates cDNA synthesis at the $3^{\prime}$ tRNA-like structure of the retroplasmid transcript (Kuiper and Lambowitz 1988; Wang et al. 1992), we suspected that it might likewise use the $3^{\prime}$ end of VS RNA as a cDNA initiation site. The $3^{\prime}$ end of VS RNA does not appear to have a tRNA-like structure but does have a $3^{\prime} \mathrm{CG}$ sequence like the $(-)$ strand of CARNA 5 satellite RNA, which is recognized as an initiation site by a cucumber mosaic virus (CMV) replicase complex (Fig. 6, bottom; Wu and Kaper 1994). However, attempts to demonstrate that cDNAs begin at the $3^{\prime}$ end of VS RNA in vivo have been unsuccessful. For wild-type VS, primer extension and $S_{1}$-nuclease mapping of $5^{\prime}$ cDNA ends in mitochondria or mt RNP particles was not possible because of the low level of reverse transcription of this element. Possibly for the same reason, attempts to clone the $5^{\prime}$ ends of wild-type VS cDNAs via anchored PCR gave no indication of a predominent initiation site and instead gave clones having $5^{\prime}$ sequences corresponding to scattered internal positions, some or all of which may be artifactually derived from closed-circular VS plasmid DNAs in the preparations (not shown).

Mapping of 5' cDNA ends was possible for VS/V1-2, which is more efficiently reverse transcribed. In this case, however, we were surprised to find that the cDNAs synthesized in RNP particles begin near the 10-bp insertion that replaces the large deletion. As shown in Figure 6 , primer extension mapping of the $5^{\prime}$ ends of the cDNAs gave a predominant doublet band, as well as lighter bands that may correspond to minor $5^{\prime} \mathrm{cDNA}$ ends or may be artifactually derived from closed-circular plasmid DNAs. The two components of the predominant doublet band map to the terminal G-residue of the 10-bp insertion and the U-residue at VS position 240. These locations were confirmed by dideoxy sequencing (Fig. $6 \mathrm{~A}$, right) and by cloning and sequencing the $5^{\prime}$ ends of the cDNAs via anchored PCR (not shown). Both of the latter methods indicated that some cDNAs may also begin within a few nucleotióes upstream or downstream of the major primer extension bands. These and other experiments in which the $5^{\prime}$ ends of cDNAs were analyzed by primer extension before and after alkali treatment did not detect potential DNA or RNA primer sequences attached to the $5^{\prime}$ ends of the cDNAs, but it remains possible that a primer is rapidly removed or is connected to the $5^{\prime}$ end of the cDNA via an unusual linkage (e.g., a $2 '-5$ ' phosphodiester bond). Although we cannot completely exclude that the 5 ' cDNA ends result from DNA cleavage rather than initiation, we could not detect such cleavage of a control ${ }^{32} \mathrm{P}$-labeled monomeric $(-)$ strand DNA incubated with RNP particles under reverse transcription conditions (not shown). Furthermore, the same 5' cDNA ends were found for endogenous cDNAs isolated from mitochondria or synthesized in 5 or $30 \mathrm{~min}$ reverse transcription reactions in RNP particles, and no additional 5' cDNA ends were found by using the VSP1 primer (see Materials and methods). Because primer extension mapping gave no indication that VS/V1-2 RNAs are cleaved near position 240 to generate a new $3^{\prime}$ end (not shown), these findings suggest that the retroplasmid $\mathrm{RT}$ initiates predominantly at an internal position in VS/ V1-2 RNA.

The structural basis for the putative internal initiation in VS/V1-2 RNA is unclear. The region around the internal site lacks a CCA sequence and does not otherwise resemble the previously described in vitro internal initiation site in the retroplasmid RNA (Wang and Lambowitz 1993a). Examination of sequences within the deleted regions showed that the 10 -bp insertion could be derived by the RT skipping between nonadjacent sequences (A-GCC-GACAAG), a mechanism suggested for 

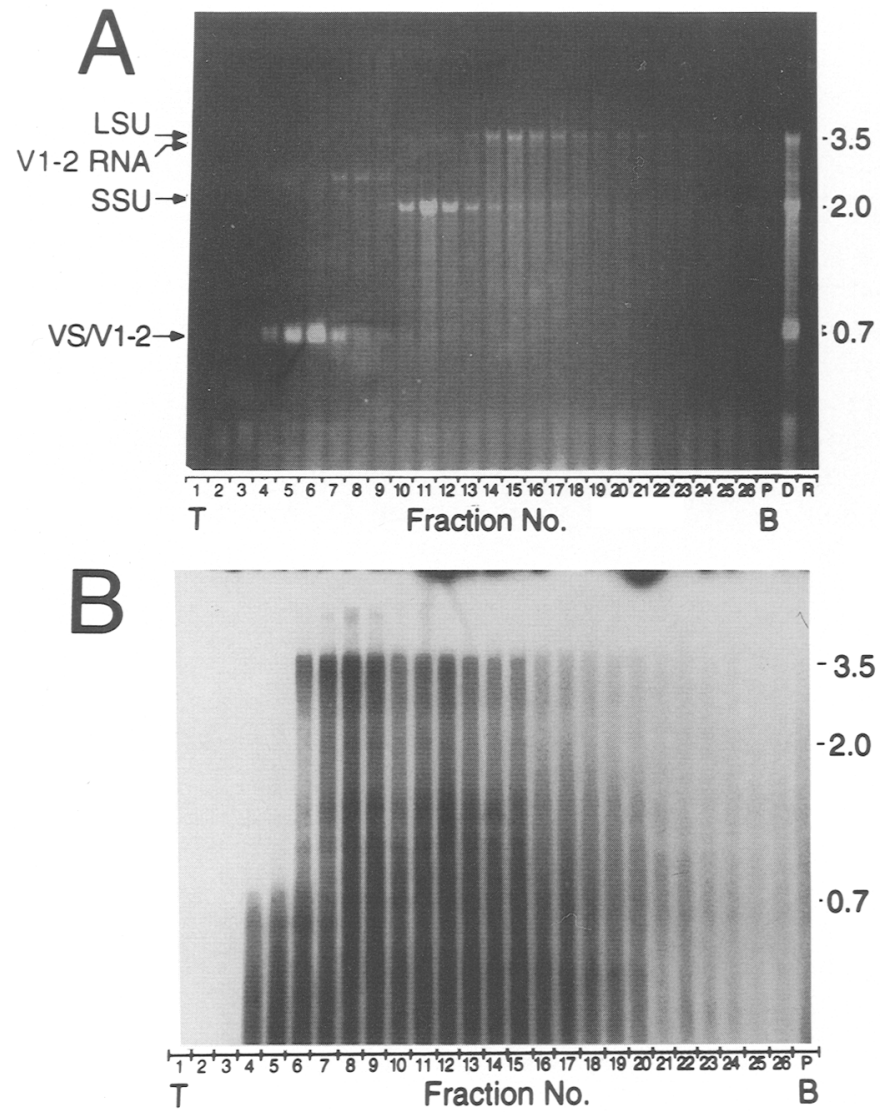
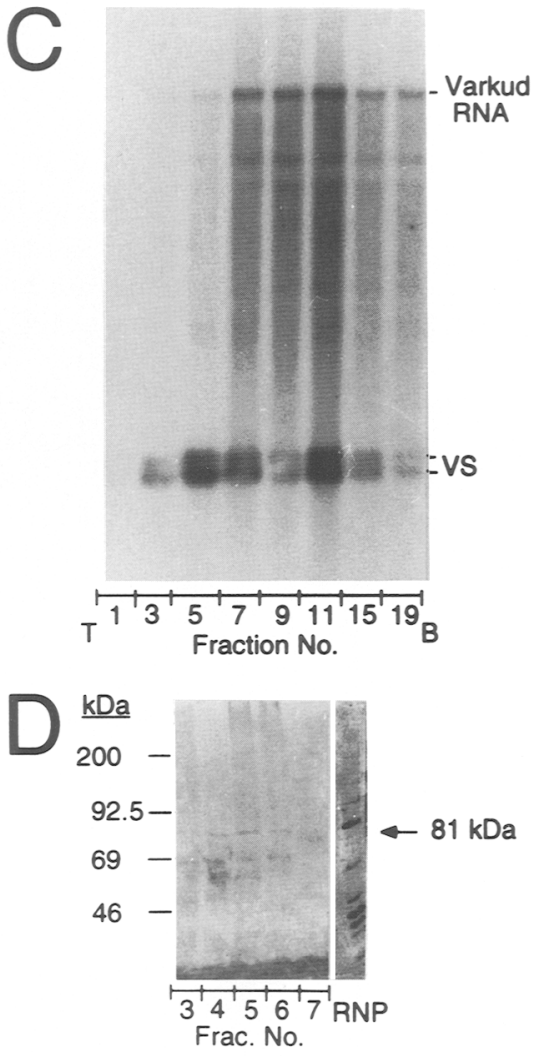

Figure 5. Sucrose gradient analysis of V1-2 mt RNP particles. Mt RNP particles were analyzed by centrifugation in a 5-20\% sucrose gradient containing $500 \mathrm{~mm} \mathrm{KCl}$ buffer, as described in Materials and methods. The high salt-sucrose gradients minimize adventitious association of proteins with RNP particles, but the RNPs tend to aggregate under these conditions at loads required to detect RT activity. $(A) \mathrm{Gel}$ electrophoretic analysis of nucleic acids from gradient fractions. Gradient fractions were ethanol-precipitated in the presence of $2 \mathrm{M}$ ammonium acetate and $20 \mu \mathrm{g}$ of Escherichia coli tRNA carrier, and nucleic acids were analyzed by electrophoresis in a $1.5 \%$ agarose gel containing $0.1 \%$ SDS. The gel stained with ethidium bromide is shown. Fractions are numbered from the top $(T)$ to the bottom $(B)$ of the gradient. Lane $P$ is the pellet recovered from the bottom of the centrifuge tube; lanes $D$ and $R$ show mt nucleic acids treated with DNase I (Pharmacia) or RNase A $+T_{1}$ (Sigma), respectively, to distinguish DNA and RNA species. Prominent RNAs are identified at left, and their sizes $(\mathrm{kb})$ are indicated at right. $(B)$ Gel electrophoretic analysis of ${ }^{32} \mathrm{P}$-labeled cDNAs synthesized in endogenous reverse transcription reactions in gradient fractions. Two-microliter portions of gradient fractions were incubated with $\left[{ }^{32} \mathrm{P} \mid \mathrm{dCTP}+\mathrm{dNTPS}\right.$, as described for endogenous reverse transcription reactions in Materials and methods, and cDNA products were analyzed by electrophoresis in a $1.7 \%$ agarose gel containing $0.1 \%$ SDS, followed by autoradiography of the dried gel. $(C)$ Hybridization of ${ }^{32} \mathrm{P}$-labeled cDNAs synthesized in the gradient fractions to a Northern blot of total mt RNA from the Varkud strain. The ${ }^{32} \mathrm{P}$-labeled cDNAs synthesized in earlier gradient fractions hybridized to VS RNA, whereas those synthesized in later gradient fractions hybridized to both VS RNA and the V retroplasmid transcript (Varkud RNA). The hybridization of ${ }^{32}$ P-labeled cDNAs in gradient fractions $9,11,15$, and 19 to VS RNA appears greater than expected from the small amounts of VS/V1-2 RNPs present in these fractions. This disproportionate hybridization likely reflects the large amount of VS RNA relative to V RNA in the Northern blot. (D) Immunoblot analysis of proteins in gradient fractions. Portions $(250 \mu \mathrm{l})$ of gradient fractions were TCA-precipitated, and proteins were analyzed by electrophoresis in a $1 \%$ SDS-10\% polyacrylamide gel. The gel was blotted to nitrocellulose and probed with antipeptide antibody 62 , which is directed against the carboxyl terminus of the retroplasmid RT (Kuiper et al. 1990). Shown are immunoblots of proteins in gradient fractions 3-7 compared with the $81-\mathrm{kD}$ RT protein detected in a mt RNP particle preparation (RNP) run in a parallel lane of the same gel. As discussed in Kuiper et al. (1990), the $81-\mathrm{kD}$ RT protein is present in very low concentrations in mitochondrial preparations and cannot be detected by immunoblotting without bringing up background bands due to nonspecific interaction of the primary or secondary antibody with more abundant proteins, particularly ribosomal proteins in the RNP particle preparations. The 81-kD protein in V1-2 mt RNP particle is not detected by preimmune serum (Kupier et al. 1990). Numbers at left indicate sizes ( $\mathrm{kD}$ ) and positions of rainbow size markers (Amersham).

similar deletion/addition mutations created by other DNA polymerases (Bebenek and Kunkel 1993). Because the cDNAs begin opposite the terminal G-residue of the 10 -bp insertion, an intriguing possibility is that the de- letion/addition event in the VS/V1-2 plasmid created a sequence or structure required for efficient internal initiation. As discussed above, it is not clear whether an internal cDNA initiation site is also used in wild-type 
VS RNA or whether initiation occurs at the $3^{\prime}$ end of the linear RNA.

\section{VS plasmid replication cycle}

Considered together with previous findings, our results for the wild-type VS and mutant VS/V1-2 plasmids suggest that these genetic elements replicate by the pathway outlined in Figure 7. The first step is transcription of the double-stranded DNA by the mt RNA polymerase starting at a cognate of the Neurospora mt DNA promoter consensus sequence. The location of the transcription start site, just upstream of the RNA self-cleavage site, suggests that linear and circular VS RNA monomers result from transcription of circular or multimeric VS DNAs combined with RNA catalyzed cleavage and ligation. This mode of RNA synthesis is analogous to the rolling circle mechanism used by other satellite RNAs, except that VS RNA is transcribed from a DNA, not an RNA, template.

Biochemical experiments showed that VS/V1-2 RNA is associated with the retroplasmid RT in RNP particles and that both VS and VS/V1-2 RNAs are reverse transcribed to yield full-length cDNAs that are presumed replication intermediates. Although the level of reverse transcription of the wild-type VS plasmid is relatively low compared to the mutant VS/V1-2, we detected (-) cDNA synthesis in both cases, whereas $|-|$ strand RNAs could not be detected by hybridization (Saville and Collins 1990). The finding that the putative cDNA initiation site is located internally in VS/V1-2 RNA suggests that

Figure 6. Primer extension mapping and sequencing of the $5^{\prime}$ ends of VS/V1-2 (-) strand cDNAs synthesized in RNP particles. (A) cDNA synthesis was carried out with V1-2 mt RNP particles in the presence $(+)$ of $125 \mu \mathrm{M}$ dNTPs. The two left panels show primer extension mapping of $5{ }^{\prime}$ cDNA ends performed with Sequenase, using $5^{\prime}{ }^{32}$ P-labeled DNA oligonucleotide primers VSP2 or VSP3 (see Materials and methods). Control lanes show parallel primer extension analysis with nucleic acids isolated from RNP particles incubated in the absence $(-)$ of dNTPs. The numbers to the left indicate the sizes /nucleotides) and positions of ${ }^{32} \mathrm{P}$-labeled PstI fragments of phage $\lambda$ DNA used as molecular weight markers. Sizes of primer extension bands are indicated at right. The right panel shows dideoxy sequencing of $(-)$ strand cDNAs using Sequenase with the $5^{\prime}$ end-labeled VSP2 primer. Lane $N$ shows a primer extension reaction carried out in parallel. The right lanes show dideoxy sequencing of $\mathrm{p} \Delta \mathrm{D} 7$, using the same $5^{\prime}$ end-labeled primer. The sequence around the $5^{\prime}$ cDNA ends is shown to the right of the autoradiograph, with the box indicating the 10 -bp insertion in VS/V1-2. The schematic beneath the autoradiographs shows the locations of primers VSP2 and VSP3, and the sizes of primer extension bands expected for a cDNA beginning opposite the G-residue at the end of the 10-bp insertion. (B) The top shows alignment of the $3^{\prime}$ ends of VS and VS/V1-2 RNAs with the $3^{\prime}$ end of CARNA $5(-)$ strand RNA (Wu and Kaper 1994). The arrow indicates the site of initiation of $1+\mid$ strand RNA synthesis in the CARNA 5 RNA. The bottom shows the sequence around the putative internal cDNA initiation site in VS/V1-2. The boxed sequence corresponds to the 10 -bp insertion. the observed monomer-length cDNAs are synthesized either from a circular or multimeric template or by template switching upon reaching the $5^{\prime}$ end of a linear RNA. Such template switching, if it occurs, would have to be very efficient, as we do not detect discrete "strong stop" cDNAs terminating opposite the $5^{\prime}$ end of the linear VS/V1-2 RNA. Following (- | strand DNA synthesis, the remaining steps in the replication of the VS plasmid presumably include displacement or degradation of the RNA template, perhaps by the endogenous $m t$ RNase $\mathrm{H}$ (Wang and Lambowitz 1993b|, synthesis of $1+\mid$ strand DNA and ligation to generate a closed circular DNA. As is the case for the retroplasmid itself, the mechanisms of $1+\mid$ strand synthesis and DNA circularization are un-
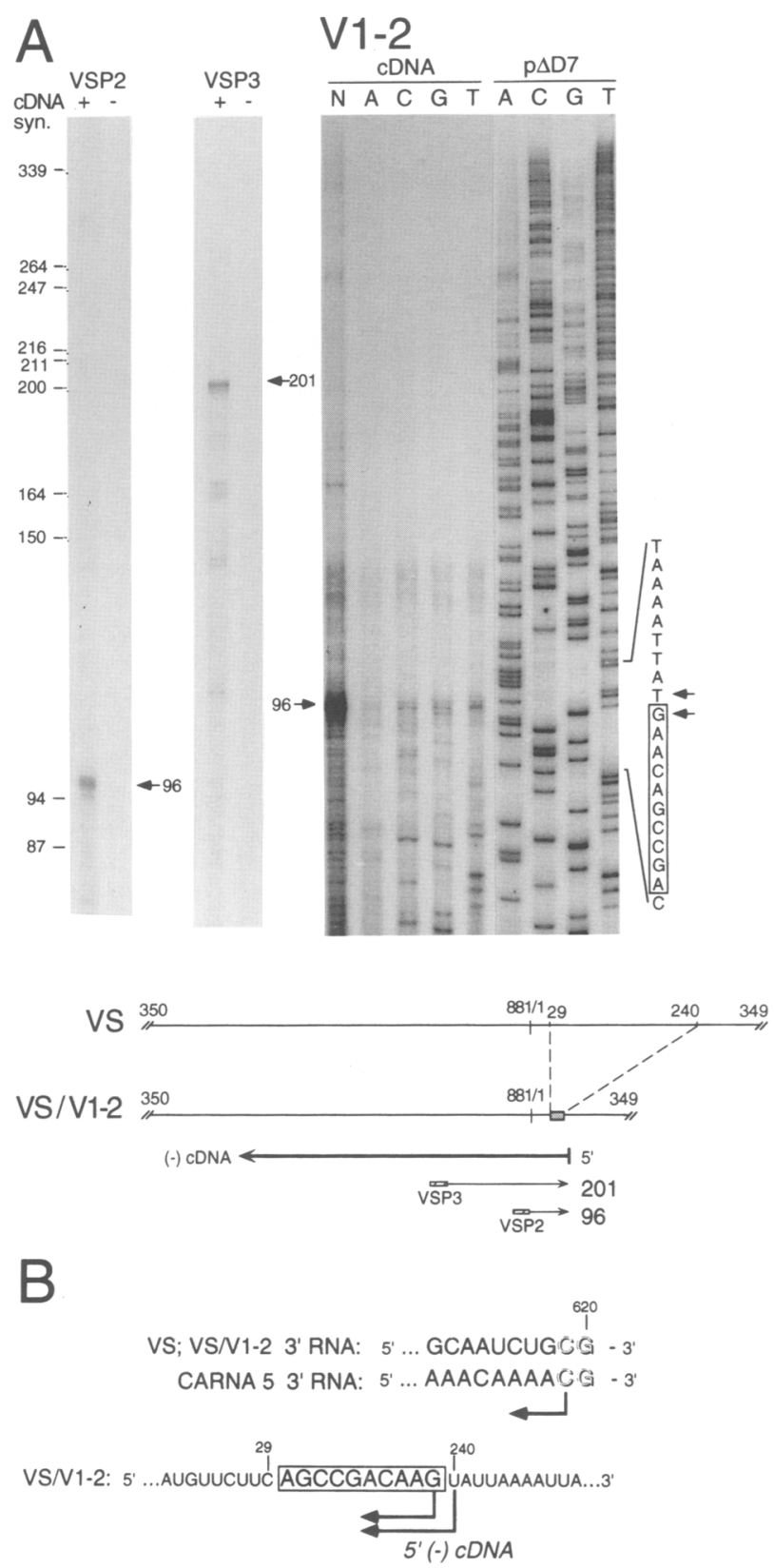


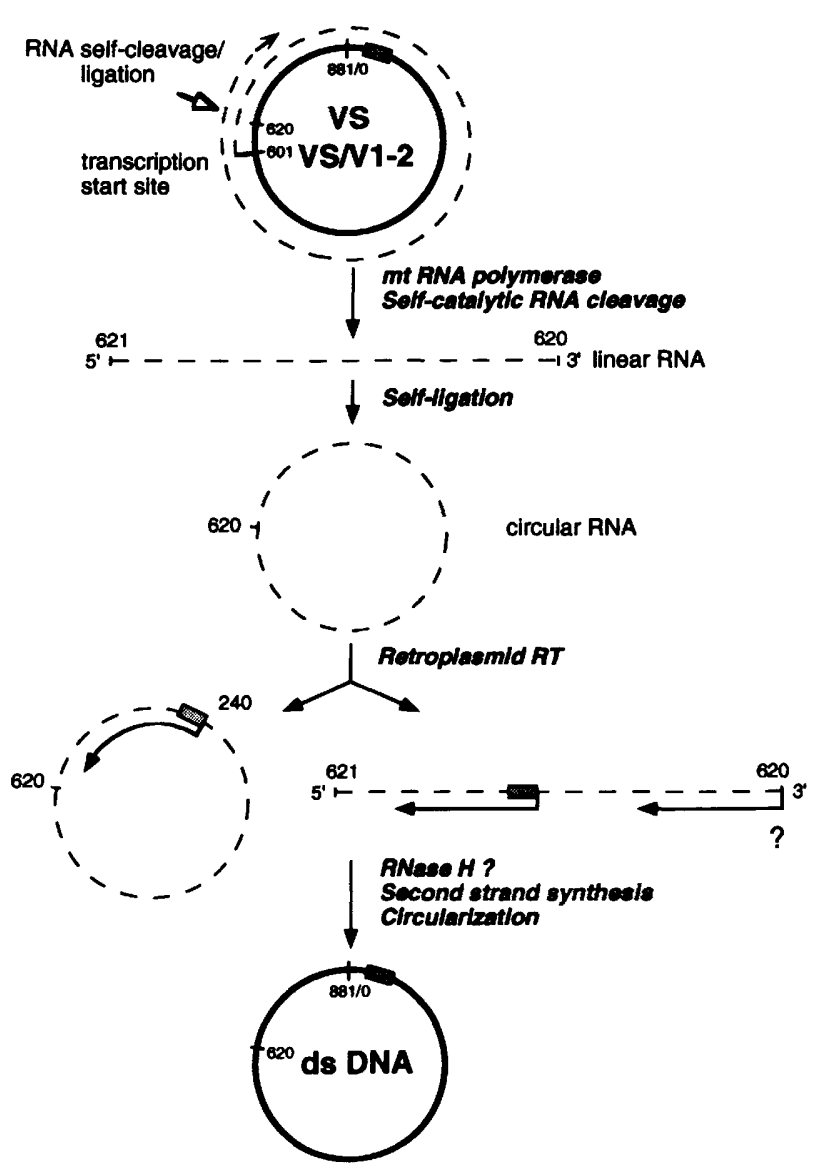

Figure 7. Proposed replication pathway of the VS and VS/V1-2 plasmids. Double-stranded VS or VS/V1-2 DNAs are transcribed by the mt RNA polymerase from a cognate of a Neurospora mtDNA promoter, with the major in vitro transcription start site corresponding to VS position 601. Linear and circular RNA monomers result from transcription of circular or multimeric DNAs coupled with RNA catalyzed self-cleavage and ligation. VS and VS/V1-2 RNAs are reverse transcribed by the retroplasmid RT to yield full-length $|-|$ strand cDNAs. For VS/ Vl-2 RNA, the predominant cDNA initiation site is located internally at the site of the deletion/addition (shaded box). Fulllength $(-)$ strand cDNAs initiated at this location could result from reverse transcription of circular or multimeric VS/V1-2 RNAs or by the RT switching templates upon reaching the $5^{\prime}$ end of a linear RNA. It is not known whether cDNA synthesis in wild-type VS RNA initiates at the $3^{\prime}$ end of the linear RNA or at an internal site. Following (-) strand synthesis, the remaining replication steps presumably include displacement or degradation of the RNA template, perhaps by the endogenous $\mathrm{mt}$ RNase $\mathrm{H}$ (Wang and Lambowitz 1993b), synthesis of (+) strand DNA, and ligation to regenerate closed circular DNA.

clear, and it is possible that a conventional DNA replication mechanism is used for the further amplification of VS DNA in mitochondria.

VS RNA is the first catalytic RNA species that appears to replicate via reverse transcription. Hepatitis $\delta$ virus, a satellite of the pararetrovirus hepatitis $B$, replicates via an RNA intermediate and depends on the helper virus for packaging (Taylor 1992). The ability of the retroplasmid to support replication of a satellite RNA presumably reflects the relative promiscuity of its $\mathrm{RT}$, which can initiate cDNA synthesis on natural RNA templates without using a complementary primer. Although the retroplasmid RT ordinarily initiates cDNA synthesis at the $3^{\prime}$ tRNA-like structure of the plasmid transcript, the solubilized RT also initiates at an internal position in the plasmid RNA (Wang and Lambowitz 1993a) and can use other RNA templates to some degree (Wang et al. 1992). The present results extend these findings by showing that the retroplasmid RT reverse transcribes an unrelated RNA species, VS RNA, in vivo and suggest further that this ability may be enhanced by the mutation in VS/V1-2 to generate a more efficient retroelement. Finally, we note that the ability of primitive RTs to reverse transcribe unrelated RNA species followed by mutational enhancement of the interaction could provide a mechanism for the evolution of new species of retroelements. Such a pathway may have been used for the generation of mobile group II introns, which appear to have acquired a RT that is phylogenetically related to the retroplasmid RT and have adapted it to function in both intron mobility and RNA splicing (Kennell et al. 1993; Lambowitz and Belfort 1993; J. Moran, S. Zimmerly, R. Eskes, J.C. Kennell, A.M. Lambowitz, R.A. Butow, and P.S. Perlman, in prep.).

\section{Materials and methods}

Neurospora strains and growth conditions

Strains used in this study were Neurospora crassa 74-OR23-1A [designated 74A; Fungal Genetics Stock Center (FGSC) no. 987] and Mauriceville-1c $A$ \{FGSC no. 2225) and Neurospora intermedia Varkud-1c (FGSC no. 1823) and senescent mutant V1-2 (FGSC no. 6006). N. crassa [poky] 13-6, which accumulates mt RNA polymerase (Barath and Kuntzel 1972; Kennell and Lambowitz 1989), was used for in vitro transcription assays. Procedures for growing the strains were as described (Kuiper and Lambowitz 1988; Kennell and Lambowitz 1989).

\section{Recombinant plasmids and phage}

Plasmid pD7 contains monomer VS DNA linearized at the DraI site and cloned in the SmaI site of the vector pTZ18R (Saville and Collins 1990). p $\Delta D 7$ contains monomer VS/V1-2 DNA linearized at the SspI site and cloned into SmaI site of pTZ18R (Pharmacia, Piscataway, NI). pS1519 contains monomer VS DNA cloned as a ScaI partial-digest fragment (VS675-674) into the SmaI site of pTZ18R. Phage M13mpM92 (M92) and M13mpM94 (M94) contain the M plasmid linearized at the SacI site and cloned into the SacI site of M13mpl8 and M13mp19, respectively (Kuiper and Lambowitz 1988). Phage V18 and V19 contain monomer VS plasmid subcloned from pS1519 between the HindIII and EcoRI sites of M13mpl 8 and M13mpl9, respectively.

\section{Isolation of $m t$ nucleic acids and RNP particles}

Mt RNA and DNA were extracted from flotation gradient-purified mitochondria, as described (Lambowitz 1979; Garriga and Lambowitz 1984). Mt RNP particles were isolated by lysing 
mitochondria with $1 \% \quad \mathrm{NP}-40$ and centrifuging the lysate through a $1.85 \mathrm{M}$ sucrose cushion containing $0.5 \mathrm{M} \mathrm{KCl}$ buffer (Garriga and Lambowitz 1986; Kuiper and Lambowitz 1988). The mt RNP particles were further purified by an additional centrifugation through the sucrose cushion to minimize associated nuclease activity.

\section{In vitro transcription by Neurospora $m t$ RNA polymerase}

For in vitro transcription, DNA templates were incubated with $\left[{ }^{32} \mathrm{P}\right]$ UTP plus other NTPs in the presence of $\mathrm{mt}$ lysates from [poky] 13-6 or the Varkud strain or with heparin-Sepharose (HS) column fractions containing partially purified mt RNA polymerase from [poky] 13.6 (Kennell and Lambowitz 1989). Transcription with $\mathrm{mt}$ lysates was done in the presence of an antibody preparation against $N$. crassa endo-exonuclease /Chow and Fraser 1983/ to inhibit nonspecific nuclease activity. ${ }^{32} \mathrm{P}$-Labeled transcripts were analyzed by electrophoresis in 6 or $12 \%$ polyacrylamide gels containing $8 \mathrm{M}$ urea, $88 \mathrm{~mm}$ Tris-borate $(\mathrm{pH}$ 8.3 ), and 2 mM EDTA (TBE), followed by autoradiography. For $5^{\prime}$ end mapping, in vitro transcription of $\mathrm{pD} 7 / S s p$ I with HS-enriched mt RNA polymerase was scaled up fivefold, and primer extension was carried out as described (Kennell and Lambowitz 1989), by using MMLV-RT (Life Science Technologies, Inc., Gaithersburg, MD| with a $5^{\prime}{ }^{32} \mathrm{P}$-labeled synthetic oligonucleotide primer $\left(5^{\prime}\right.$ GTAGTCAACTGCTACGAC, complementary to nucleotide positions VS702-685.)

\section{Endogenous reverse transcription reactions in $m t$ RNP particles}

Endogenous reverse transcription reactions were carried out in $20 \mu \mathrm{l}$ of reaction medium containing $2 \mu \mathrm{l}$ of $\mathrm{mt}$ RNP particles ( $\sim 0.04 A_{260}$ units), $100 \mathrm{~mm} \mathrm{KCl,} 6 \mathrm{mM} \mathrm{MgCl}_{2}, 50 \mathrm{~mm}$ Tris- $\mathrm{HCl}$ (pH 8.3), $5 \mathrm{~mm}$ dithiothreitol, $125 \mu \mathrm{m}$ each dATP, dGTP, dTTP, and $20 \mu \mathrm{Ci}$ of $\left[\alpha^{-}{ }^{32} \mathrm{P}\right] \mathrm{dCTP}(3000 \mathrm{Ci} / \mathrm{mmole}$; Dupont/NEN, Boston, MA) (Kuiper and Lambowitz 1988; Kennell et al. 1994). The reactions were incubated for $10 \mathrm{~min}$ at $37^{\circ} \mathrm{C}$, "chased" for 10 min with $100 \mu \mathrm{M} \mathrm{dCTP}$, and terminated by extraction with phenol/chloroform/isoamyl alcohol $(25: 24: 1)$. The products were incubated with $0.2 \mathrm{M} \mathrm{NaOH}$ and then were ethanol precipitated (Kennell et al. 1994). For time course experiments, the dCTP chase was omitted.

\section{Hybridization analysis of ${ }^{32}$ P-labeled cDNAs}

The ${ }^{32} \mathrm{P}$-labeled cDNAs synthesized in endogenous reverse transcription reactions were hybridized to Northern or Southern blots of mt RNAs or DNAs, respectively, or to dot blots of M13-cloned ( +) or (-) strands of the mt plasmids. ${ }^{32} \mathrm{P}$-Labeled cDNAs probes were dissolved in $20 \mu \mathrm{l}$ of $10 \mathrm{mM}$ Tris- $\mathrm{HCl} / \mathrm{pH}$ 8.01 , $1 \mathrm{~mm}$ EDTA, and boiled for $5 \mathrm{~min}$ at $95^{\circ} \mathrm{C}$. Southern hybridizations were carried out with gels blotted to Hybond $\mathrm{N}$ membranes (Amersham, Chicago, IL), as described (Kuiper and Lambowitz 1988). For Northern hybridizations, mt RNAs were denatured with glyoxal and analyzed by electrophoresis in $1.4 \%$ agarose gels containing $10 \mathrm{~mm}$ sodium phosphate buffer (McMaster and Carmichael 1977). Gels were blotted to Hybond N membranes and hybridized as described for Southern blots (Kuiper and Lambowitz 1988). Dot blots were done on Hybond $\mathrm{N}$ membranes in a Minifold SRC 96 dot blot apparatus (Schleicher \& Schuell, Keene, $\mathrm{NH}$ ) with $0.5 \mu \mathrm{g}$ of single-stranded DNA in each well. The dot blots were prehybridized for $12 \mathrm{hr}$ at $37^{\circ} \mathrm{C}$ in $2.5 \mathrm{ml}$ of $40 \%$ formamide, $1 \mathrm{M} \mathrm{NaCl}, 50 \mathrm{mM} \mathrm{Na}_{2} \mathrm{PO}_{4}$ (pH 7.0), $1 \%$ SDS, $0.2 \mathrm{mg} / \mathrm{ml}$ salmon sperm DNA, and $5 \times$ Denhardt's solution (Denhardt 1966), and then hybridized with the ${ }^{32} \mathrm{P}$ - labeled cDNAs $\left(10^{4}-10^{5} \mathrm{cpm}\right)$ in the same solution for $48 \mathrm{hr}$ at $37^{\circ} \mathrm{C}$. The blots were washed twice with $2 \times$ SSC (SSC $=150$ $\mathrm{mM} \mathrm{NaCl}, 15 \mathrm{~mm} \mathrm{Na}$ citrate), $0.5 \%$ SDS for $20 \mathrm{~min}$ at room temperature, and then twice with $0.5 \times$ SSC, $0.5 \%$ SDS for 20 $\min$ at $37^{\circ} \mathrm{C}$, prior to autoradiography.

\section{Sucrose gradient analysis}

Ten $A_{260}$ units of mt RNP particles from the V1-2 strain were resuspended in $91 \mu \mathrm{l}$ of $\mathrm{HKCTD}\left[500 \mathrm{mM} \mathrm{KCl}, 50 \mathrm{mM} \mathrm{CaCl}_{2}, 25\right.$ $\mathrm{mM}$ Tris- $\mathrm{HCl}$ (pH 7.5), $5 \mathrm{~mm}$ dithiothreitol] plus $1 \mathrm{~mm}$ spermidine and $1 \mathrm{~mm}$ phenylmethylsulfonyl fluoride and incubated with $1 \mathrm{~mm}$ puromycin (Sigma, St. Louis, MO) for $5 \mathrm{~min}$ at $37^{\circ} \mathrm{C}$. The RNPs were then centrifuged through a 5-20\% sucrose gradient containing HKCTD (Beckman SW41 rotor, 40,000 rpm, 3 $\mathrm{hr}$ at $4^{\circ} \mathrm{Cl}$, and fractions of $0.43 \mathrm{ml}$ were collected. $\mathrm{MgCl}_{2}$ ordinarily used in sucrose gradients was replaced with $\mathrm{CaCl}_{2}$, which suppresses nuclease activity while preserving the integrity of ribosomal subunits (Lambowitz 1979).

\section{Primer extension mapping of cDNA $5^{\prime}$ ends}

cDNAs for primer extension mapping were synthesized in 10fold, scaled-up endogenous reverse transcription reactions containing $125 \mu \mathrm{M} \mathrm{dNTPs}$ and $100 \mu \mathrm{g} / \mathrm{ml}$ of actinomycin D (Boehringer Mannheim, Indianapolis, IN). Primer extension mapping of alkali-treated cDNAs was carried out as described (Kennell et al. 1994), with Sequenase (U.S. Biochemical, Cleveland, OH) with $5^{\prime}{ }^{32}$ P-labeled oligonucleotide primers (VSP1, 5'-ACATGGCTGTAGGTGTGAGA, corresponding to nucleotide positions VS450-469; VSP2, 5'-TCTGTAGCAATCTCTTCCGCC, corresponding to VS826-846; or VSP3, 5'-GGCTAAGTGACGGTATTGGCG, corresponding to VS721-740). The primer extension products were analyzed by electrophoresis in $6 \%$ polyacrylamide $/ 8 \mathrm{M}$ urea gels containing TBE. Dideoxy sequencing of the cDNAs with the VSP2 primer (Sanger et al. 1977) was carried out in parallel.

\section{Acknowledgments}

This work was supported by National Institutes of Health grant GM37949 to A.M.L. and grants from the Medical Research Council of Canada and Natural Sciences and Engineering Research Council of Canada to R.A.C. We thank Mr. James Williams for technical assistance.

The publication costs of this article were defrayed in part by payment of page charges. This article must therefore be hereby marked "advertisement" in accordance with 18 USC section 1734 solely to indicate this fact.

\section{References}

Akins, R.A., D.M. Grant, L.L. Stohl, D.A. Bottorff, F.E. Nargang, and A.M. Lambowitz. 1988. Nucleotide sequence of the Varkud mitochondrial plasmid of Neurospora and synthesis of a hybrid transcript with a $5^{\prime}$ leader derived from mitochondrial RNA. I. Mol. Biol. 204: 1-25.

Akins, R.A., R.L. Kelley, and A.M. Lambowitz. 1989. Characterization of mutant mitochondrial plasmids of Neurospora spp. that have incorporated tRNAs by reverse transcription. Mol. Cell. Biol. 9: 678-691.

Barath, Z. and H. Kuntzel. 1972. Induction of mitochondrial RNA polymerase in Neurospora crassa. Nature 240: 195197.

Beattie, T.L., J.E. Olive, and R.A. Collins. 1995. A secondary model for the self-cleaving region of Neurospora VS RNA. Proc. Natl. Acad. Sci. (in press).

Bebenek, K. and T.A. Kunkel. 1993. The fidelity of retroviral 
reverse transcriptases. In Reverse transcriptase led. A.M. Skalka and S. P. Goff), pp. 85-102. Cold Spring Harbor Laboratory Press, Cold Spring Harbor, New York.

Chiang, C.-C., J.C. Kennell, L.A. Wanner, and A.M. Lambowitz. 1994. A mitochondrial retroplasmid integrates into mtDNA by a novel mechanism involving the synthesis of a hybrid cDNA and homologous recombination. Mol. Cell. Biol. 14: 6419-6432.

Chow, T.Y.-K. and M.J. Fraser. 1983. Purification and properties of single strand DNA-binding endo-exonuclease of Neurospora crassa. J. Biol. Chem. 258: 12010-12018.

Collins, R.A. and B.J. Saville. 1990. Independent transfer of mitochondrial chromosomes and plasmids during unstable vegetative fusion in Neurospora. Nature 345: 177-179.

Collins, R.A., L.L. Stohl, M.D. Cole, and A.M. Lambowitz. 1981. Characterization of a novel plasmid DNA found in mitochondria of N. crassa. Cell 24: 443-452.

Denhardt, D.T. 1966. A membrane-filter technique for the detection of complementary DNA. Biochem. Biophys. Res. Commun. 23: 641-646.

Eickbush, T.H. 1994. Origin and evolutionary relationships of retroelements. In Evolutionary biology of viruses (ed. S.S. Morse), pp. 121-157. Raven Press, New York.

Garriga, G. and A.M. Lambowitz. 1984. RNA splicing in Neurospora mitochondria: Self-splicing of a mitochondrial intron in vitro. Cell 39: 631-641.

- 1986. Protein-dependent splicing of a group I intron in ribonucleoprotein particles and soluble fractions. Cell 46: 669-680.

Guo, H.C.T., D.M. De Abreu, E.R.M. Tillier, B.J. Saville, J.E. Olive, and R.A. Collins. 1993. Nucleotide sequence requirements for self-cleavage of Neurospora VS RNA. I. Mol. Biol. 232: 351-361.

Kennell, J.C. and A.M. Lambowitz. 1989. Development of an in vitro transcription system for Neurospora crassa mitochondrial DNA and identification of transcription initiation sites. Mol. Cell. Biol. 9: 3603-3613.

Kennell, J.C., J.V. Moran, P.S. Perlman, R.A. Butow, and A.M. Lambowitz. 1993. Reverse transcriptase activity associated with maturase-encoding group II introns in yeast mitochondria. Cell 73: 133-146.

Kennell, J.C., H. Wang, and A.M. Lambowitz. 1994. The Mauriceville plasmid of Neurospora spp. uses novel mechanisms for initiating reverse transcription in vivo. Mol. Cell. Biol. 14: 3094-3107.

Kubelik, A.R., J.C. Kennell, R.A. Akins, and A.M. Lambowitz. 1990. Identification of Neurospora mitochondrial promoters and analysis of synthesis of the mitochondrial small rRNA in wild-type and the promoter mutant [poky]. J. Biol. Chem. 265: 4515-4526.

Kuiper, M.T.R. and A.M. Lambowitz. 1988. A novel reverse transcriptase activity associated with mitochondrial plasmids of Neurospora. Cell 55: 693-704.

Kuiper, M.T.R., J.R. Sabourin, and A.M. Lambowitz. 1990. Identification of the reverse transcriptase encoded by the Mauriceville and Varkud mitochondrial plasmids of Neurospora. I. Biol. Chem. 265: 6936-6943.

Lambowitz, A.M. 1979. Preparation and analysis of mitochondrial ribosomes. Methods Enzymol. 59: 421-433.

Lambowitz, A.M. and M. Belfort. 1993. Introns as mobile genetic elements. Annu. Rev. Biochem. 62: 587-622.

McMaster, G.K. and G.G. Carmichael. 1977. Analysis of singleand double-stranded nucleic acids on polyacrylamide and agarose gels by using glyoxal and acridine orange. Proc. Natl. Acad. Sci. 74: 4835-4848.

Roossinck, M.J., D. Sleat, and P. Palukaitis. 1992. Satellite
RNAs of plant viruses: Structures and biological effects. Microbiol. Rev. 56: 265-279.

Sanger, F., S. Nicklen, and A.R. Coulson. 1977. DNA sequencing with chain-terminating inhibitors. Proc. Natl. Acad. Sci. 74: 5463-5467.

Saville, B.J. and R.A. Collins. 1990. A site-specific self-cleavage reaction performed by a novel RNA in Neurospora mitochondria. Cell 61: 685-696.

1991. RNA-mediated ligation of self-cleavage products of a Neurospora mitochondrial plasmid transcript. Proc. Natl. Acad. Sci. 88: 8826-8830.

Song, C. and A.E. Simon. 1994. RNA-dependent RNA polymerase from plants infected with turnip crinkle virus can transcribe $(+1$ - and $(-1$-strands of virus-associated RNAs. Proc. Natl. Acad. Sci. 91: 8792-8796.

Symons, R.H. 1992. Small catalytic RNAs. Annu. Rev. Biochem. 61: 641-671.

Taylor, J.M. 1992. The structure and replication of hepatitis delta virus. Annu. Rev. Microbiol. 46: 253-276.

Wang, H. and A.M. Lambowitz. 1993a. The Mauriceville plasmid reverse transcriptase can initiate cDNA synthesis de novo and may be related to reverse transcriptase and DNA polymerase progenitor. Cell 75: 1071-1081.

1993b. Reverse transcription of the Mauriceville plasmid of Neurospora. Lack of ribonuclease $\mathrm{H}$ activity associated with the reverse transcriptase and possible use of $\mathrm{mi}$ tochondrial ribonuclease H. I. Biol. Chem. 268: 1895118959.

Wang, H., J.C. Kennell, M.T.R. Kuiper, J.R. Sabourin, R. Saldanha, and A.M. Lambowitz. 1992. The Mauriceville plasmid of Neurospora crassa: Characterization of a novel reverse transcriptase that begins cDNA synthesis at the $3^{\prime}$ end of template RNA. Mol. Cell. Biol. 12: 5131-5144.

Wu, G. and J.M. Kaper. 1994. Requirement of 3'-terminal guanosine in $(-)$-stranded RNA for in vitro replication of cucumber mosaic virus satellite RNA by viral RNA-dependent RNA polymerase. I. Mol. Biol. 238: 655-657.

Wu, G., J.M. Kaper, and E.M.J. Jaspars. 1991. Replication of cucumber mosaic virus satellite RNA in vitro by an RNAdependent RNA polymerase from virus-infected tobacco. FEBS Lett. 292: 213-216.

Wu, G., I.M. Kaper, and S.D. Kung. 1993. Replication of satellite RNA in vitro by homologous and heterologous cucumoviral RNA-dependent RNA polymerases. Biochimie 75: 749-755.

Xiong, Y. and T.H. Eickbush. 1990. Origin and evolutionary relationships of retroelements based upon their reverse transcriptase sequences. EMBO /. 9: 3353-3362. 


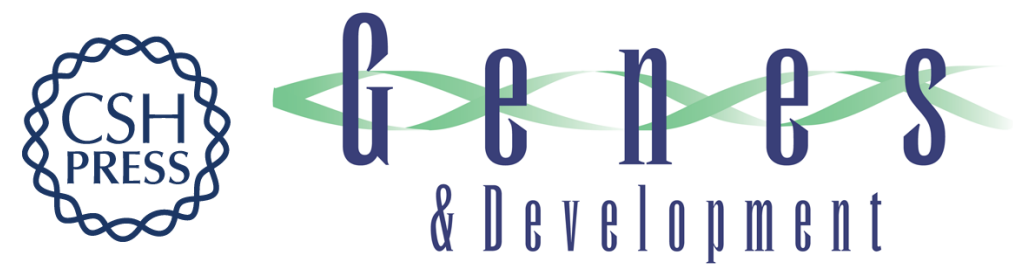

\section{The VS catalytic RNA replicates by reverse transcription as a satellite of a retroplasmid.}

J C Kennell, B J Saville, S Mohr, et al.

Genes Dev. 1995, 9:

Access the most recent version at doi:10.1101/gad.9.3.294

References This article cites 34 articles, 14 of which can be accessed free at:

http://genesdev.cshlp.org/content/9/3/294.full.html\#ref-list-1

License

Email Alerting

Service

Receive free email alerts when new articles cite this article - sign up in the box at the top right corner of the article or click here.

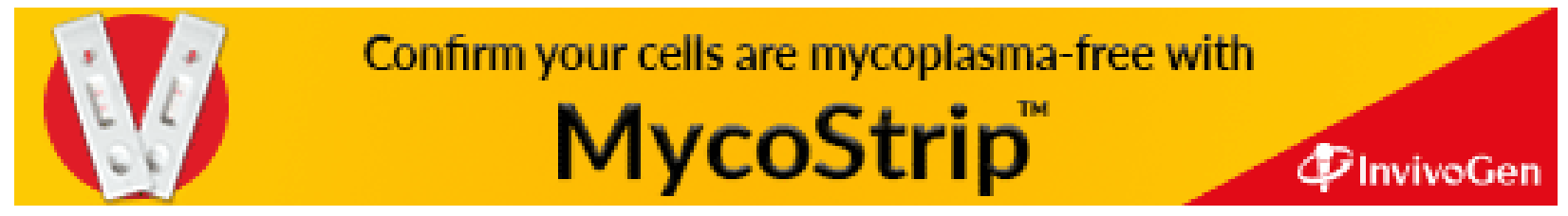

